\title{
De lo privado a lo público: Estudio de las relaciones de género en el sistema patriarcal fang de Guinea Ecuatorial
}

\author{
From Private to Public: Study of Gender Relations \\ in The Fang Patriarchal System of Equatorial Guinea
}

\section{Resumen}

El presente artículo tiene el objetivo de llevar a cabo un análisis sobre las relaciones de género en el sistema patriarcal fang, las cuales están marcadas por la diferenciación de los espacios privado (para las mujeres) y público (para los hombres). Para este análisis, se ha utilizado una metodología descriptiva, la cual nos ha permitido a través de la revisión bibliográfica, argumentar sobre la cuestión que aquí se aborda. Uno de los principales resultados de esta investigación está en haber puesto de manifiesto que la mujer fang ha estado confinada en el espacio privado o la casa-cocina, donde servía para parir hijos y dedicarse al cuidado del hogar. Las ideas de emancipación de la mujer que pregona la ideología feminista han propiciado que en la sociedad ecuatoguineana, las mujeres se propongan despatriarcalizar la cultura androcentrista que las ha estado infravalorando. Por eso, es importante estabilizar los logros obtenidos hasta ahora.

Palabras clave: espacio, fang, género, subordinación, patriarcado.

\begin{abstract}
This article aims to carry out an analysis of gender relations in the patriarchal fang system, which are marked by the differentiation of private (for women) and public (for men) spaces. For this analysis, a descriptive methodology has been used, which has allowed us, through the bibliographic review, to argue about the question that is addressed here. One of the main results of this research is to have revealed that the Fang woman has been confined in the private space or the house-kitchen, where she served to give birth to children and dedicate herself to taking care of the home. The ideas of emancipation of women that the feminist ideology proclaims have caused women in Equatoguinean society to de-patriarchalize the androcentric culture that has been undervaluing them. Therefore, it is important to stabilize the achievements obtained so far.

Keywords: space, fang, gender, subordination, patriarchy.

\section{SUMARIO}

Introducción. 1.- El sistema patriarcal fang. 2.- De lo privado a lo público: la lucha contra el sistema patriarcal fang. Conclusiones. Bibliografía.
\end{abstract}

\section{Introducción}

Si algo ha caracterizado las relaciones de género en el sistema patriarcal fang de Guinea Ecuatorial, es la clara diferencia establecida entre el espacio público que 
corresponde a los hombres, y el espacio privado que corresponde a las mujeres. Durante muchos años, estas relaciones de género han mostrado la asimetría que existía en el pueblo fang con respecto a lo que debía ser masculino y femenino.

El propósito de este trabajo es llevar a cabo un análisis sobre cómo el sistema patriarcal fang relegó a la mujer en un status quo sempiterno de subordinación al hombre. En este sentido, hemos visto oportuno utilizar la metodología descriptiva, la cual nos ha permitido conocer mejor, la naturaleza del sistema patriarcal fang.

Por otra parte, también se exponen aquí la toma de conciencia de las mujeres para salir del yugo patriarcal. Se analizan las diferentes etapas de lucha y resistencia contra el patriarcado que ha sido la causa de la emulación de lo femenino, es decir, ha creado a la mujer ecuatoguineana gracias a la utilización de una serie de estereotipos y una socialización diferenciada cuyo fin es el adoctrinamiento masivo de la mujer para que esta no se revele contra el sistema patriarcal. Por eso, los principales interrogantes que se van a desentrañar en este trabajo son los siguientes: ¿en qué consiste el sistema patriarcal fang? ¿existe alguna diferencia entre el espacio privado y el público dentro de la etnia fang?

Dar respuesta a estos interrogantes es una prioridad porque conlleva a entender y argumentar de manera rigurosa sobre las relaciones de género en sistema patriarcal fang de Guinea Ecuatorial. Para responder a estos interrogantes, vamos apoyarnos en algunas autoridades científicas del ámbito académico.

Cabe decir que debido a la escasez de estudios de género sobre el sistema patriarcal fang, nos basaremos principalmente en los textos que se manejan dentro de la teoría feminista para conceptualizar y politizar de esta forma, las desigualdades entre lo masculino y lo femenino. La identidad de la mujer fang es producto de lo que han querido los hombres que sea, de hecho, su rol fundamental siempre ha sido el cuidado de la prole. La mujer es concebida como un ser complementario que ayuda al hombre a satisfacer sus apetitos sexuales. En otras palabras, " en la cultura Fang-Bantú, el rol de la mujer se ha creado bajo un sistema de dominación masculina que se conoce con el nombre de patriarcado» (Bituga-Nchama, 2020: 16). Por tanto, el problema que se plantea está en que las diferencias entre los espacios privado y público, han sido llevadas a cabo por un sistema patriarcal de coacción dentro de la etnia fang, donde la mujer se ha convertido en un ser construido para servir y acompañar al hombre. Esta aseveración tiene su fundamento en el androcentrismo que se observa en la etnia fang, el cual permite aducir y corroborar que es una cultura patriarcal pensada y hecha para privilegiar sistemáticamente a los varones en detrimento continuo de las mujeres, privándolas de su propia autonomía y condicionándolas a estereotipos de género.

Los estereotipos de género son un mal para las sociedades porque representan el dominio histórico que el hombre viene ejerciendo sobre la mujer. Por lo que, su análisis resulta crucial para entender la dominación masculina que el sistema patriarcal de Guinea Ecuatorial ejerce sobre la mujer para mantenerla en un status constante de dominio y subordinación, en todas las facetas de las relaciones interhumanas. 


\section{El sistema patriarcal fang}

El origen de la dominación de la mujer se encuentra en el sistema patriarcal impuesto por los hombres. Se trata de un pacto muy longevo del que no podemos rastrear su origen, debido al hecho de que se trata de una cultura ágrafa, que no logró desarrollar la escritura, es decir, la palabra escrita. Por eso, todas las narraciones de este pueblo se han transmitido de manera oral, a través de los relatos mitológicos sobre su genealogía.

Por cuestiones metodológicas, antes de desarrollar u ofrecer un análisis sobre los fang, lo primero que tenemos que hacer es una descripción detallada sobre este grupo étnico. Los fang son un grupo étnico que habita en varios países del África Central, con una cultura bien consolidada. Siguiendo la línea de reflexión, Nsang Ovono señala que:

Los Fang constituyen el grupo étnico más numeroso de la República de Guinea Ecuatorial. Originarios del interior de la región continental, conocida como Río Muni, es posible encontrarlos en la actualidad en todas las provincias del país y se estima que constituyen el noventa por ciento de la población del mismo. Más allá de las fronteras ecuatoguineanas se encuentran distribuidos por los países vecinos, constituyendo uno de los grupos étnicos más numerosos de la áfrica central. (Nsang Ovono, 2018: 33-48)

En este mismo orden de ideas, «[...] hemos de decir que se trata de un pueblo que se rige por el sistema de clanes, cuyo grupo base es la familia horizontal, y cuyos miembros están agrupados alrededor de un patriarca» (Bolekia Boleká, 2003: 25). Tal como puede observarse, se trata de un pueblo con su propia organización, lo cual constituye los cimientos de su cultura. En esta cita del profesor Bolekia Boleká, hay un dato que es importante subrayar, y es que, los fang se organizan en torno al patriarca, una figura investida de poder el cual ejerce su voluntad sobre los suyos. Este mismo esquema de funcionamiento, es el que se traslada al ámbito del hogar donde el hombre establece lo que es privado y público, porque es el jefe, el que manda y la mujer tiene que obedecerle. Cuando hablamos de sistema, nos referimos a un entramado bien organizado donde el poder es ejercido por unos sobre otros. $\mathrm{O}$, mejor dicho, el funcionamiento de ciertas instituciones es posible gracias a la visión de unos. De igual modo, si constituimos la juntura sistema patriarcal, entiéndase lo patriarcal como aquello que marca u establece dentro de un sistema o estructura, las relaciones entre los sexos, no obstante, el patrón principal en estas relaciones es la desigualdad entre estos dos sexos. Sobre la cuestión del patriarcado, Amelia Valcárcel señala lo siguiente:

La teoría feminista intentó llevarla a cabo mediante el constructo conceptual al que llamó patriarcado [...] Patriarca, patriarcal, patriarcado son términos presentes desde antiguo en nuestra tradición cultural pero cuyo sentido valorativo ha cambiado en los últimos tiempos. [...] Patriarcal era sinónimo de anciano, venerable, sabio, reposado. (Valcárcel, 1991: 137- 138) 
En este sentido, dentro del sistema patriarcal, las relaciones de género son totalmente desiguales entre los sexos, como ocurre dentro de la cultural fang. El sistema patriarcal fang no es un producto de hoy, sino más bien se trata de un sistema muy longevo, con varios siglos de existencia en los que la temática fundamental siempre ha sido la opresión hacia la mujer. Hay que reconocer que las mismas mujeres también contribuyen a mantener vivo ese sistema. Decimos contribuyen porque al ser adoctrinadas por el sistema patriarcal, las mismas han trasmitido o reproducido las pautas de comportamiento aprendidas. La escasez de estudios feministas, sobre las relaciones de género en el sistema patriarcal fang ha propiciado que la situación de la mujer se vea hasta hace bien poco, como algo natural. Sin embargo, los pocos estudios existentes sobre el sistema patriarcal fang, lo detallan en los siguientes términos:

La lógica que sigue el sistema patriarcal fang permite o coloca al hombre en el centro de todas las cosas, de allí que sea una cultura androcéntrica donde los varones disponen lo que creen conveniente que deben hacer las mujeres. En suma, toman decisiones sobre sus sentimientos y comportamientos, incluso sobre su propia reproducción. En efecto, al partir del hecho de que la mujer es un ser débil, se da por sentado que el hombre debe hacerse cargo de ella, mientras que, por su parte, la mujer debe complacer a su esposo. Esta educación ha sido posible gracias a la creación de una serie de estereotipos que representan a la mujer como una auténtica sumisa al varón. (Bituga-Nchama, 2020: 145)

Como ha ocurrido en muchas partes, el sistema patriarcal es la manifestación de la autoridad feroz del hombre sobre la mujer. Este sistema patriarcal, que, en principio, se ha vivido y se vive en otras sociedades, "se caracteriza por la autoridad de los hombres sobre las mujeres y sus hijos impuesta desde las instituciones» (Castells, 1998: 159).

El sistema patriarcal es discriminatorio con las mujeres. Durante mucho tiempo ha sido la ley que regía el comportamiento de los hombres y las mujeres en la comunidad. Se trata de una arquitectura sistemáticamente establecida por los hombres para beneficiarles. De todas las instituciones patriarcales que tiene el sistema patriarcal fang, el matrimonio representa el principal foco de desigualdades entre hombres y mujeres. Para asegurar esta continuidad de su legado, se ha tenido que subyugar a la mujer para que solo se dedique hacer posible la continuidad del legado de los hombres. Un primer paso sobre el matrimonio Fang, nos lleva asegurar que el consentimiento de los cónyuges es Conditio sine qua non para la celebración del matrimonio. Con esta línea argumentativa, queremos decir que para que una mujer se case debe dar su consentimiento.

A la luz de esta investigación debemos dejar claro que no estamos en contra del uso del Nsóa o dote en el matrimonio fang, pues consideramos que es parte de las idiosincrasias de esta cultura. No obstante, el punto de fricción de esta temática lo encontramos en la cosificación a la que se ha reducido a la mujer con su práctica. La cual es consentido por la llamada cultura moderna fang o aquella cultura que intenta coexistir en un mundo absorbido con la globalización. En correspondencia con lo anterior, conviene recordar que: 
Nuestro Nsuáh [...] es actualmente el dinero que la familia del [...] hombre suele entregar a la familia de la novia que viene a ser su esposa, para que el matrimonio [...] [consuetudinario] sea legítimo, jurídico y garantizado. El nsuah era un moderador de tensiones; anteriormente, no era dinero lo que se daba por él.

(Esono Mitogo, 1990: 39-41)

La situación actual de la dote en el matrimonio fang, convierte a la mujer en un objeto que tiene precio. A raíz de esto, existen dos posturas ideológicas sobre el estado actual de la dote en la etnia fang. Por una parte, están las posturas a favor de la dote, y por otra, se encuentran las que opinan en contra de la dote. Para las posturas ideológicas a favor de la dote, viendo la situación actual, no abogan por su abolición, sino más bien insisten en un renacimiento del sentido original de la dote fang. Analizan varios aspectos en los que la dote se convierte en el epicentro o la piedra angular del matrimonio fang. Si se elimina la dote, el matrimonio en la cultura fang quedaría sin sentido, porque eso significaría tener que adoptar otra fórmula para realizar los enlaces matrimoniales.

Quizás se piense que lo fácil sería adoptar el matrimonio canónico, pero eso podría resultar incongruente, ya que no es algo culturalmente de los fang, por eso, una opción que no se debería explorar. En sucesivas ocasiones se ha llegado afirmar que «el matrimonio por la dote (nsua) coexiste con el matrimonio canónico. Las esposas tienen los mismos derechos, aunque existen diferencias respecto a aquella esposa con la que se ha contraído matrimonio canónico» (Nzé Abuy, 1985: 24). En este sentido, se respetaba la dote por ser el medio en el que el hombre fang se realiza como tal, por engendrar los hijos y constituir una familia. Para los fang no se puede hablar de matrimonio sin dote, por eso, se debe legitimar la unión matrimonial pagando la dote.

En las antípodas de las posturas ideológicas a favor de la dote, se hallan aquellas que están en contra de la dote en la cultura fang. El principal problema que actualmente se observa con la dote, está en el descomunal que se pide para que dos personas puedan contraer legalmente matrimonio. En la sociedad tradicional fang, la dote se concebía como un símbolo de unión entre dos familias.

En relación a lo anterior, Mbana Nchama señala que «lo que la sociedad fang buscaba en el matrimonio no era el interés pecuniario, sino la cooperación interclánica» (Mbana Nchama, 2016: 75). No obstante, es evidente que la postura de Mbana Nchama ha quedado obsoleta en la actualidad. Decimos obsoleta porque el matrimonio fang persigue el interés pecuniario, y no solamente la felicidad y el bienestar de los cónyuges. Por consiguiente, no es extraño que, en una de las investigaciones publicadas recientemente sobre la dote, se señale que: «por mucha apología que se quiera hacer de la dote como un elemento cultural y símbolo de unión en la cultura fang [...] la dote otorga al hombre la facultad de decidir y tomar decisiones en la vida de la mujer [...]» (Bituga-Nchama, 2020: 15-27). Desde la perspectiva de este autor, la dote se presenta como un elemento cultural del que se vale el hombre para oprimir a la mujer. Es un planteamiento no ajeno a la hora de analizar la dote en la etnia fang, pues, si la mujer es un objeto de compraventa, su marido asume de esta manera la posesión de aquello que ha comprado. 
El precio que se pide actualmente para casarse con una mujer, pone en debate si realmente la mujer tiene precio o no. Lo cierto es que, para aquellos que están en contra de la dote, la misma debe abolirse, porque entre otras cosas, lacera la dignidad de la mujer. El investigador Pérez Armiño, es quien lo ha descrito detalladamente, porque parte del supuesto de que el matrimonio conoció un cambio brusco con la introducción del dinero. De forma taxativa, señala que:

Se entiende como un asunto económico que se concreta a través de la dote, la cual adquiere la forma de una inversión a corto plazo. La mujer es entendida como símbolo de riqueza. El hombre poseerá tantos campos como mujeres puedan cultivarlos. A largo plazo, cuantas más mujeres, más probabilidad de incrementar la familia mediante el nacimiento de niñas, que en un futuro serán intercambiadas por una dote en forma monetaria. (Pérez Armiño, 2018: 30-59)

Tal como reza el viejo aforismo latino, la persona humana es, y debería ser res extra commercium, esto significa que en ningún momento puede ser concebido o tratado como algo o cosa. Sin embargo, esto no siempre es así, y no lo decimos precisamente porque hablamos de la dote, sino porque la misma historia es efectivamente, magistra vita, al enseñarnos los errores que hemos cometido en nuestro camino. La mujer se vio cosificada con la introducción del dinero en la cultura fang. Incluso, en base a los argumentos y posturas que presentamos en esta investigación, nos atrevemos a sostener que, con el dinero la mujer pasa a ser más infravalorada que antes. De hecho, un padre con hijas solo piensa en sus muchas dotes, no tanto en sus propias hijas, porque las concibe como una mercancía o negocio.

$\mathrm{Al}$ respecto, son varios los problemas que la mujer fang tiene que enfrentar a lo largo de su vida, pero el más terrible es tener que aprender a ser mujer de acuerdo a los cánones que la cultura establece para ellas. Como individuo perteneciente a la cultura fang, la mujer está llamada al respeto de estas normas, siempre y cuando no perjudiquen su dignidad. Por tanto, es importante hacer una revisión de estas normas culturales que fueron establecidas por los varones, en un momento del que no se tienen referencias escritas. Por consiguiente, dentro del sistema patriarcal fang, la opresión y las injusticias que sufren las mujeres frente a los hombres en nuestros entornos, son catapultadas por la existencia de obstáculos como los estereotipos de género que dictan y determinan la manera en la que la gente tiene que comportarse o actuar en función de su sexo. Detrás de todo eso, está la discriminación que sufre la parte femenina en manos de los hombres. El patriarcado habría que entenderlo como una ideología que favorece solo y únicamente a los hombres, en detrimento de las mujeres.

Manuel Iradier, uno de los primeros exploradores de las tierras españolas de la Guinea Española, en la parte continental donde se encuentran las tribus fang, llegó apuntar que: «el regateo entre el padre de la novia y el pretendiente [...] llega a abandonar teatralmente la casa de la palabra tratando de obtener la ventaja económica en la negociación. El novio ofrece sus regalos, que deben satisfacer la dote» (Iradier, 1887: 224-225).

Los regalos del novio, debían ser de entrada, atractivos porque era una manera de demostrar que se ama a la mujer y se haría cualquier cosa por ella. El dinero que 
se podía obtener de las mujeres era suficiente para conseguir otros artículos, por eso, la mujer se habría convertido en un objeto de compraventa.

\section{De lo privado a lo público: la lucha contra el sistema patriarcal fang}

Para entender las relaciones de género en el sistema patriarcal fang, es imperativo rastrear los orígenes de este sistema, ya que lo único que observamos son sus diferentes manifestaciones. Sin embargo, es una verdadera odisea para los estudiosos de las relaciones de género, ubicar el momento concreto en que lo masculino apartó a lo femenino. Todo ello es debido también a la escasez de los estudios de género en Guinea Ecuatorial. Las desigualdades entre los sexos son muy visibles, pero no existe una conceptualización temática sobre esta cuestión para politizar.

Desde tiempos inmemoriales de los que se tienen poquísimos datos, la mujer fang siempre ocupó el espacio privado, un lugar donde tenía completa autoridad, aunque era una autoridad supeditada a la de su marido.

El espacio privado es la cocina de la mujer, donde se ocupaba de preparar los alimentos para su marido y para sus hijos. Era el lugar donde se encontraba con sí misma como persona. Este espacio representaba su propia vida porque ahí podía hacer lo que quisiera. Hay que destacar que el espacio privado existe para que la mujer pueda organizarse y atender bien a su marido. Normalmente, este espacio público estaba vetado a los hombres, aunque esto era en teoría porque se trataba de una zona ubicada dentro de la casa de los conyugues donde vivían con su familia. Los varones podían acceder a la cocina de la casa siempre y cuando lo deseaban y las mujeres no se oponían. Todas las tareas domésticas las niñas las aprendían en este espacio público donde sus madres las enseñaban a cocinar para que en el futuro aquellas hagan lo mismo con sus maridos. Por consiguiente, es evidente que:

Los diferentes espacios entre las mujeres y los hombres también han permitido que los estereotipos género establecidos por el sistema de educación patriarcal, se consoliden de tal forma que cada uno de los sexos desempeñe su rol. Resulta que, al observar los roles, los hombres están en una situación de dominio, mientras que las mujeres se convierten en dominadas. Por tanto, no puede decirse que el patriarcado esté erradicado en la sociedad ecuatoguineana, al contrario, está muy robustecido, aunque actualmente sufre ciertas presiones de parte de las activistas feministas de esta sociedad. Lo cierto es que los estereotipos de género son aspectos de la vida cotidiana de la sociedad ecuatoguineana, creado por los hombres y reproducido por las mujeres, por eso, resulta también difícil salir de esta situación. (Bituga-Nchama, 2020: 153)

El confinamiento de las mujeres en el espacio privado comenzó en el periodo precolonial del que se tienen pocos datos. Pero es posible que haya sido así porque el sistema patriarcal fang es muy longevo. Por eso, «es prácticamente imposible ofrecer una descripción fidedigna de la realidad de la mujer Fang precolonial» (Pérez Armiño, 2018: 32).

Por lo tanto, cuando hablamos aquí del espacio público, trascurrimos dentro del periodo colonial y el postcolonial hasta 1979. Más adelante, explicaremos por qué 
esta fecha es todo un hito que va a cambiar drásticamente la vida de todas las mujeres de Guinea Ecuatorial. Sobre la historia de la mujer dentro del sistema patriarcal fang, nos encontrarnos con:

Una periodización de la historia de la mujer guineana en dos grandes etapas [...] de acuerdo a su grado de dependencia respecto a las estructuras masculinas imperantes en cada momento. La mujer dependiente, que engloba tanto a la mujer fang sometida a una sociedad rígidamente patriarcal como es la fang; pero también la mujer guineana, nativa, dependiente de la administración colonial española, también patriarcal, y en exceso paternalista. Todas las políticas desarrolladas durante la fase colonial en la actual Guinea Ecuatorial tenían una visión paternalista demasiado cínica. La mujer, tanto en periodo precolonial como durante la dominación española, es considerada un simple objeto. (Mbana Nchama, 2011: 121)

Partiendo de este planteamiento, el período colonial puede considerarse como un momento en el que la dependencia de la mujer era total. El patriarcado todavía estaba muy arraigado en la etnia Fang. El espacio femenino y masculino se ha establecido en función del sexo. Por eso, el espacio privado era reservado a las mujeres, porque ellas no podían dedicarse a los peligros de fuera (la caza y otras tareas). Luis Pérez Armiño ofrece una explicación del espacio privado en el sistema patriarcal fang, señalando que:

La casa-cocina es el espacio femenino básico, donde la mujer desarrolla gran parte de sus actividades junto con sus hijos no iniciados a la edad adulta. Allí, cuando la mujer no está trabajando los campos, cocina para los hombres. La casacocina es un espacio femenino durante las horas del día. Los hombres acuden allí durante la noche para descansar o para mantener relaciones sexuales con las mujeres. Desde una óptica masculina, para el fang la casa-cocina es el lugar donde se asegura la producción y la reproducción del grupo, a través de la comida y a través de las relaciones sexuales respectivamente [...] En la casa-cocina se guarda el ajuar femenino, aquel destinado a la producción de alimentos. (Pérez Armiño, 2018: 42)

A través de este espacio, los varones mantenían resguardadas a las mujeres para que estén protegidas y seguras mientras ellos estaban fuera, o en el abaa charlando y esperando ser servidos. Este espacio privado que Pérez Armiño denomina casacocina, es el germen de las desigualdades. Además, es el espacio que ayuda mantener el estereotipo de mujer dependiente y sumisa.

Para precisar mejor sobre el estudio de las relaciones de género en el sistema patriarcal fang, tenemos que señalar que el sexo juega un papel muy importante para establecer las diferencias entre hombres y mujeres. Por su parte, téngase en cuenta que, «cuando hablamos de sexo nos referimos a la biología -a las diferencias físicas entre los cuerpos de las mujeres y de los hombres-, y al hablar de género, a las normas y conductas asignadas a hombres y mujeres en función de su sexo» (Varela, 2005: 181). Estas diferencias biológicas de las que habla Valera, son tenidas muy en cuenta en el sistema patriarcal a la hora de establecer las diferencias 
entre lo que corresponde a las mujeres y a los hombres en función de sus sexo. Por poner un ejemplo, en la etnia fang, algunos objetos marcaban prácticamente una diferenciación sexual entre los hombres y las mujeres. Las mujeres que estaban en el espacio privado, tenían un tipo de utensilios y los hombres también tenían otros. En otras palabras, existen testimonios en los que se detalla la diferenciación sexual en función de los utensilios que utilizaban los fang. En este sentido, se aduce que:

Otro marcador material que nos informa de las relaciones de género establecidas entre los Fang es la cuchara. Había dos tipos básicos, unas femeninas y las otras masculinas. Las primeras, las de la mujer, eran piezas simples, sin apenas decoración, de largo mango y pala lisa. Se utilizaban exclusivamente para preparar los alimentos. De hecho, las mujeres utilizaban otras cucharas y otros instrumentos para comer, en ocasiones simples conchas u hojas, trozos de calabaza sin apenas modificación. Sin embargo, las cucharas masculinas tienen una enorme complejidad tipológica y decorativa. (Pérez Armiño, 2018: 43)

Por consiguiente, esta diferenciación en cuanto a los utensilios era una manera para exaltar la grandeza y el poder de los hombres. Debían resaltar su megalomanía para verse fuertes y poderosos dentro de su cultura. Es totalmente comprensible que las cucharas de los hombres tuviesen una enorme complejidad tipológica porque solo de esta manera se podía diferenciar la cuchara del hombre con la de la mujer. Hay que especificar que las cucharas de los hombres no podían ser utilizadas por las mujeres para comer o cocinar, porque aquello se interpretaría como una falta de respeto y desconsideración a la autoridad del hombre. Sin embargo, el único momento en el que las mujeres entraban en contacto con estos utensilios masculinos era cuando tenían que lavarlos. No obstante, es imposible destacar que en algún momento las mujeres hayan utilizado estos utensilios, al menos no para que sus esposos se den cuenta de ello. Estos distintos precedentes de discriminación van un poco más allá porque al confinar a las mujeres en el espacio privado que es la casa-cocina, el hombre quedó exento de todo lo relacionado con este espacio. Así, por ejemplo, era imposible encontrar o concebir que un hombre cocinase porque se entendía que era una actividad que debían ejercer las mujeres. Esa manera de entender o ver las cosas ha llegado hasta la actualidad, donde los hombres siguen desdeñando el hecho de cocinar.

La lógica que se sigue en esta cuestión está en que si el hombre se pone a cocinar, se convertiría en un ser servicial de la mujer. Es decir, se pondría él a servir a la mujer para que esta pueda comer, algo totalmente inaudito. La mujer debe cocinar porque es su labor hacerlo para dar de comer al hombre. Es evidente que en función del sexo de la mujer se la ha asignado la tarea de tener que cocinar para el hombre. Como señalábamos ut supra, este pensamiento es el que nos ha llegado hasta hoy, donde los hombres desprecian cocinar, pero se alimentan con gusto de la comida que preparan las mujeres. Es una manera de robustecer el sistema patriarcal, con estereotipos de género bien establecidos para que no se alteren las cosas.

Tradicionalmente las actividades económicas del pueblo fang son: la caza, la pesca y la agricultura. En estas actividades económicas también encontramos una 
asignación de tareas en función del sexo. En lo que se refiere a la caza, sólo los hombres podían tener acceso a ella, no porque las mujeres no pudiesen, simplemente porque así estaba establecido en la concepción del sistema patriarcal fang. Se consideraba la caza como una práctica que requiere de muchísima astucia y fuerza, algo que evidentemente, no se encontraba en las mujeres. En cuanto a la pesca, era practicada por hombres y mujeres, aunque había una modalidad de caza para cada uno de sexos. Por tanto, «era individual o colectiva, según los casos. Esta última era especialmente practicada por las mujeres» (Nvé Bengobesama, 1981: 105). Por último, también tenemos que enfocarnos en la agricultura. La vida del campo es llevada a cabo por hombres y mujeres, aunque hay algunas tareas específicas para los hombres y las mujeres. Al respecto, Tessmann sostiene que:

El trabajo más duro y agotador corresponde a los hombres, el más sencillo a las mujeres. Quizás pueda pensarse que las mujeres tenían menos trabajo, pero según el autor citado anteriormente, llevar cargas tremendas, que deforman el cuerpo femenino, es en parte culpa de las propias mujeres. (Tessmann, 2003: 113)

Situándonos en las antípodas de este pensamiento de Tessmann, sostenemos que el hecho de llevar cargas tremendas es debido a todo lo que tiene que transportar las mujeres para llevarlo al hogar de su marido. Si los hombres llevasen toda esta carga, no se deformaría el cuerpo de las mujeres. Ese autor comete un fallo de raciocinio porque se olvida que las mujeres son las que continúan con la siembra y la cosecha del campo, mientras los hombres están en el abaa. La actividad del campo es una actividad muy vinculada a las mujeres. Aunque los hombres intervienen en la primera fase, son las mujeres las que continúan con este oneroso trabajo. En líneas generales, hay que reconocer que:

\footnotetext{
El trabajo de los campos era una actividad femenina. Los fang, asentados en un determinado espacio, procedían a su explotación. Los hombres debían desbrozar los campos. Una vez limpios, se dividían en tantos terrenos como mujeres había en la comunidad. Se iniciaba entonces el periodo de siembra, cuidado y recolección de las cosechas, actividades que llevaban a cabo las mujeres. (Pérez Armiño, 2018: 44)
}

Al ver lo importante que era la mujer para el campo, comenzó a ser considerada como riqueza. Eso es lo que también explica la tendencia polígama del hombre fang porque el disponer de una buena plantilla de mujeres ayuda bastante para la siembra y cosecha. Ocupar el espacio privado siempre ha supuesto una subordinación para las mujeres de Guinea Ecuatorial. Por eso, insistimos en que es necesario partir de estas divisiones para estudiar el sistema patriarcal de la cultura ecuatoguineana en general.

Los espacios están bien diferenciados, para que la mujer ocupe lo privado y el hombre lo público. Se debe respetar estas normas culturales para que la sociedad avance con equilibrio. No obstante, ese equilibro es un supuesto, ya que el hombre siempre impone su voluntad para que la mujer le obedezca. Por ejemplo, en la sociedad ecuatoguineana, hay un estereotipo común a todas las mujeres, nos re- 
ferimos a que siempre están en casa y cuidando a los hijos, es decir, siempre están ocupando el espacio privado que suele ser, como se ha dicho ut supra, la cocina. Mientras tanto, los hombres se ocupan de proveer y suministrar alimento a sus familias. La existencia de estos estereotipos frenan considerablemente el avance de las mujeres, además, hacen que sean más propensas a sufrir cualquier tipo de violencia de parte de su marido.

El espacio privado de la mujer siempre ha estado sustentado por estereotipos de género. De hecho, en la etnia fang, existe una concepción de la mujer bien establecida por el sistema patriarcal. Esta concepción establece que:

Las mujeres, tal y como el estereotipo las retrata, serán consideradas como naturalmente destinadas a la vida privada, a la maternidad y al cuidado de la familia. Y poco interesadas por cualquier otra actividad, especialmente aquellas vinculadas al ámbito público. (Bosch \& Ferrer, 2003: 119)

Por tanto, esta manera de pensar coadyuva a confinar a las mujeres para que no tengan acceso a lo público porque este espacio corresponde exclusivamente a los hombres. En síntesis, el espacio público es de ad usum privatum, sólo para los varones. A la mujer fang le corresponde el $f a$, así se denomina el espacio privado en fang, la zona de las mujeres, mientras que los hombres ocupan el nseng, un lugar privilegiado solo para los hombres. Esta división ha sido la que ha marcado las relaciones de género en Guinea Ecuatorial. Donde guiándose por el sexo de la gente, se le ha confiado o asignado determinados roles que debía realizar para toda la vida.

Tras realizar el análisis del espacio privado $(f a)$, conviene ofrecer también una reflexión sobre el espacio público (nseng), eso para entender por qué solo debía ser ocupado por los hombres. En la etnia fang, el espacio público era el abáa o la casa de palabra, un lugar privilegiado donde se reunían los hombres para charlas o abordar los temas más importantes de la tribu. Este lugar estaba situado justo en el centro de la aldea, representaba un punto central donde se ejercía la autoridad patriarcal. Teniendo en cuenta la peculiaridad de este espacio, es necesario describirlo meticulosamente. El profesor Longinos Eseng Nguema Bilogo ofrece una descripción detallada del $a b a a$, y lo hace en estos términos:

El término abá'a se deriva de dos verbos transitivos: áhbæh y ábee. El verbo áhbæh significa «escuchar atentamente» a los otros y a uno mismo [...] El abá'a, pues, más que «casa de la palabra», es principalmente, «la casa de la escucha», lugar de calma, de sosiego y de tranquilidad, donde las conversaciones se desarrollan en un ambiente distendido, de sinceridad y de confianza total. (Nguema Bilogo, 2012: 72-73)

En esta misma línea, continúa diciendo que:

Cuando los chicos llegan a la adolescencia, les exigen estar en el abá'a con los adultos, donde aprenden la filosofía fang y la cultura ancestral, así como la moral social. El adulto que frecuentaba la cocina era menospreciado por la comunidad 
y apodado, despectivamente, Bekábefefam (hombre afeminado). Los menesteres de las niñas en la cocina son, principalmente, aprender de la madre a preparar la comida y a ocuparse de otras labores domésticas. (Nguema Bilogo, 2012: 55)

En estas dos citas se recoge uno de los argumentos que hemos presentado anteriormente, al sostener que en el sistema patriarcal fang, la mujer tiene mayor representatividad en el espacio privado, que es la casa-cocina, donde prepara los alimentos que su marido trae al hogar, y se los lleva al espacio público que es, en primer lugar, el comedor de la casa, y en segundo lugar, el patio-abaa, donde su marido suele quedarse para charlar con sus iguales.

Partiendo de estos planteamientos, el abaa era el lugar por excelencia de los hombres, el cual estaba vetado a las mujeres, quienes solo podían entrar en este lugar para traer la comida a los hombres. Además, la presencia de la mujer en el abaa también era posible si los hombres quisiesen tratar un asunto de gran urgencia en el que deberían intervenir las mujeres. Esto lo decimos basándonos en hechos como que la mujer fang, no tenía acceso al espacio público que era el abaa, aunque después de una larga tradición y conciencia de reivindicaciones contra un sistema patriarcal opresor como el nuestro, las mujeres consiguieron tener acceso a este espacio público que solo se consideraba propio de los varones. De hecho, Constantino Ocháa Mvé Bengobesaman expone la siguiente idea:

Cuando los niños llegaban al uso de razón compartían la vida con los mayores en el abaa, con cuya convivencia aprendían muchas cosas de la vida laboral de los hombres: coser la nipa para la construcción, tejer las nasas y cestas de pescar y preparar cualquier género de trabajo artesano. (Nvé Bengobesama, 1981: 201)

Como se puede observar, el mencionado autor solo habla de que los niños eran los únicos que tenían acceso a ese lugar. En ningún momento menciona a la mujer porque está claro que el lugar de la mujer estaba en la cocina. La lucha de las mujeres por salir de este confinamiento, se ha centrado sobre todo en hacerse con el espacio público. Conviene matizar que no ha sido fácil para la mujer ecuatoguineana de hoy poder superar o salir del espacio privado al público. Las relaciones de género en el sistema patriarcal fang se han producido en tres periodos bien diferenciados. El período precolonial, el colonial y el poscolonial.

El período precolonial corresponde al momento más férreo de la subordinación de la mujer, donde su dependencia al hombre era total. De este período se tienen muy pocos testimonios escritos. No obstante, partiendo del patrón cultural fang, se puede deducir que es en este periodo donde se forjaron todos los estereotipos de género tanto para los hombres como para las mujeres. Esta organización o manera de etiquetar a la gente es la que ha llegado hasta nuestros días. En cuanto al período colonial, hay que precisar que el status de la mujer continúa siendo el mismo. Es un período que va de 1958 hasta 1968. Los colonos españoles trataron a la mujer partiendo de la manera que lo hacían los mismos nativos. Además, tampoco se podía esperar que el trato a la mujer nativa fuese diferente, ya que, incluso en España, en este período la igualdad era un espejismo. Así lo corrobora Elies Furió al señalar que: 
El papel de mujer era el estereotipo de madre y ama de casa y el del hombre el ser el proveedor material para la familia. Este adoctrinamiento no varió sustancialmente en el periodo de apertura del franquismo, sin duda la religión era una fuente de legitimación de este estereotipo de feminidad... (Alonso Pérez y Furió Blasco, 2007: 9)

Partiendo de esta realidad que se vivía en España durante el periodo de la colonización española en Guinea Ecuatorial, es evidente que el trato hacia la mujer nativa iba a ser el mismo que recibían las españolas en la metrópoli. El período poscolonial comienza en 1968, año en que Guinea Ecuatorial accede a la independencia. Durante este período, hubo un ligero avance porque se comienza a contemplar la posibilidad de que las niñas también puedan estudiar como los niños, aunque todavía seguía muy presente la idea de que la mujer debía estar solo en la cocina y casada con algún hombre. Uno de los acontecimientos que marcan un antes y un después en la historia de las relaciones de género en Guinea Ecuatorial, fue el golpe de libertad o alzamiento militar de 1979, que el actual presidente de Guinea Ecuatorial llevó a cabo contra Francisco Macías Nguema Biyogo.

El acontecimiento de 1979 es sin lugar a dudas, un verdadero golpe de libertad donde se abre una nueva historia sobre todo para las mujeres. Este acontecimiento hizo que gracias al gobierno de Obiang las mujeres pudiesen estudiar o que pudiesen decidir con quién casarse sin la coacción de sus familias. A raíz de esto y de acuerdo con Castells, es justo decir que «... hemos presenciado lo que supone una insurrección masiva de las mujeres contra su opresión en todo el mundo, si bien con intensidad diferente según la cultura y el país » (Manuel, 2000:159-269). Esta voluntad de encaminar hacia el cambio de una relaciones caracterizadas anteriormente por la subordinación de la mujer al hombres, a otras nuevas caracterizadas por la igualdad de género, tomaron otro sentido cuando el gobierno actual de Guinea Ecuatorial ratificó la Convención sobre la Eliminación de Todas las formas de Discriminación contra la Mujer (CEDAW), el 23 de Octubre de 1984, y el Protocolo de la Carta Africana de Derechos Humanos y de los Pueblos, también conocido como el Protocolo Maputo. Además, el cambio cultural también ha sido posible gracias a la difusión de la ideología feminista en Guinea Ecuatorial. La cual ha permitido entre otras cosas, que las mujeres cuestionen aquellos preceptos culturales que las subyugan a los hombres. Esta ideología feminista no ha sido bien recibida, por eso el sistema patriarcal fang pretende ahora reorganizarse para evitar que la mujer se independice o que tenga autonomía sobre su propia vida. Hay un peligro real en relación a los logros que ha conseguido la mujer ecuatoguineana en general para salir de lo privado a lo público. Existe una amenaza constante que pretende detener todo lo conseguido hasta ahora. Algunos investigadores sostienen que:

La mujer debe recuperar y hacer una revisión crítica del fa, el espacio privado, que ocupaba la parte trasera de las casas tradicionales fang. Lo contrario sería simplificar la visión del papel femenino en la sociedad guineana de acuerdo a los parámetros occidentales. El fa es «la propiedad más preciosa de la mujer», un 
espacio central del poblado donde se decide la vida de la comunidad frente al nseng, un espacio superficial y traicionero. Ahora bien, la mujer independiente debe tomar una decisión sobre el lugar que quiere ocupar en la sociedad: el fa o el nseng, la visión tradicional o la occidental. (Mbana Nchama, 2011: 127-129)

La postura que presenta Mbana Nchama es retrógrada, no se debe volver hacer una revisión crítica de nada. Ningún paso atrás para volver al espacio privado. La visión tradicional relega a la mujer en un ámbito que la oprime, lo cual es intolerable para la visión moderna, no occidental. Preferimos hablar de visión moderna porque en ella la mujer fang puede decidir sin ninguna influencia occidental y si lo hiciese, eso tendría que ayudarla a trazar su futuro. No se puede cometer un error de raciocinio al pensar que el fa, el espacio privado, la casa-cocina, es el mejor lugar para la mujer. Se ha descrito anteriormente en qué consistía este espacio. Por estar en él, las mujeres quedaron excluidas del conocimiento porque no eran consideradas aptas para esta labor. En la actualidad, la conciencia feminista que se registra en Guinea Ecuatorial no tiene precedentes. Su propósito es destruir el espacio privado donde el sistema patriarcal:

Ha cosificado y mercantilizado a la mujer de una forma extrema [...] Determinados sectores de la población femenina se han movilizado en un nuevo activismo que pretende ver en la tradición Fang los principios que han justificado ideológicamente la dominación de la mujer. (Pérez Armiño, 2018: 55-56)

En suma, seguir desmontando el espacio privado es la vía a seguir hacia el camino de la igualdad, modificando así las relaciones de género en el sistema patriarcal fang de Guinea Ecuatorial. Los distintos espacios; privado y público, también han permitido que los estereotipos establecidos por el sistema patriarcal, se consoliden, de tal forma que, cada uno de los sexos desempeñe su rol. Si bien los estereotipos de género afectan a hombres y mujeres, conviene poner de manifiesto que, "son éstas las que padecen los efectos más perjudiciales. Como reflejo de las diferencias de género, los estereotipos refuerzan y justifican las asimetrías de poder y mantienen lo femenino en una posición de subordinación» (Onofre de Alencar, 2015: 33). Resulta que al observar los roles, los hombres están en una situación de dominio, mientras que las mujeres se convierten en dominadas. Pese a encontrar etnias en Guinea Ecuatorial que aparentemente son matriarcales como es el caso de la etnia Bubi, hay que señalar que el patriarcado es un patrón cultural a todas las etnias del país. Teniendo en cuenta la premisa de que el patriarcado es un sistema de dominación, este utiliza la categoría de género para oprimir, infravalorar y subordinar sistemáticamente a la mujer.

Refiriéndonos al término género constatamos que es una diferencia de tipo social que el sistema patriarcal utiliza para establecer lo masculino y femenino. El género no es biológico sino social, siendo un poco más precisos, «... es una construcción cultural correspondiente a los roles o estereotipos que en cada sociedad se asignan a los sexos» (Elósegui, 2011: 47). Esto da entender que tanto hombres como mujeres somos productos de una construcción social y no biológica, al menos, eso es lo que se deduce con la explicación que se ofrece dentro de la perspectiva femi- 
nista. Somos conscientes que en este trabajo abordamos solo y exclusivamente la situación de la mujer ecuatoguineana, pero el término mujer es el mismo en todas las culturas a pesar de algunas diferencias en el trato que reciben hacia los hombres, creemos que son prácticamente iguales porque todas nos enfrentamos en mayor o menor grado al sistema patriarcal.

\section{Conclusiones}

Partiendo de todo el análisis anterior, se llega a la conclusión de que las relaciones de género en el sistema patriarcal fang, todavía se rigen desde la perspectiva androcéntrica. A pesar de haberse producido una revolución feminista dentro de la etnia fang, el patriarcado sigue siendo muy vigente en la sociedad ecuatoguineana. A veces, se observa un ligero cambio para deconstruir el sistema patriarcal, pero en una sociedad donde prevalece en gran medida lo masculino, es muy difícil, pero no imposible que se logre o se visualice en atisbo de igualdad.

El presente estudio aporta una conceptualización académica sobre las relaciones de género en el sistema patriarcal fang de Guinea Ecuatorial. Al mismo tiempo, corrobora las posturas feministas al presentar el patriarcado como un sistema de subordinación universal que se ha dado en todas las partes del mundo. Tal y como se habrá podido observar la diferenciación de los espacios privado y público, es una consecuencia directa de cómo se construye lo que es para varones y lo que es para las mujeres. Esta construcción es evidentemente patriarcal, ejercida o establecida por los hombres. Por tanto, no es de extrañar que las mujeres hayan quedado confinadas en el ámbito de lo privado. El comportamiento de la mujer fang se ha forjado desde el ámbito de lo privado. Todos los estereotipos de género con los que tiene que lidiar la mujer se han transmitido desde el ámbito privado. Ahora bien, hay que señalar que han sido las mismas mujeres las que han llevado a cabo la enseñanza de los valores más rancios del patriarcado fang. Se han ido reproduciendo pautas de comportamiento que las niñas aprendían de sus madres en la casa-cocina, el espacio privado. Eso ha sido así porque los varones aislaron a las mujeres en este espacio para que se quedasen allí a criar a la prole.

El espacio privado, es el lugar donde las niñas aprendían a ser mujeres y se las preparaba para convertirse en buenas madres y esposas. Todo lo concerniente al hogar es lo que debían aprender las niñas para que cuando se casen hagan lo mismo con sus hijas. Al atrincherar a las mujeres en el espacio privado, el sistema patriarcal fang anulaba así la posibilidad de una sororidad. Cada mujer debía estar en su propia casa sin estar mucho en compañía de las demás, eso para evitar que aquellas se pusiesen a pensar en otras cosas que no sean las funciones que están llamadas a ejercer. A demás de esto, también es mérito del sistema patriarcal el haber difundido la creencia de que las mujeres no se llevan bien entre ellas y por eso no tienen que estar juntas. Con este pensamiento bien arraigado en el sistema patriarcal fang, las mujeres estaban solas y no tenían espacios para poder hablar de sus cosas como lo hacían los hombres. Aniquilar la sororidad fue crucial para que se mantuviese incuestionable el sistema patriarcal fang. 
Por tanto, el objetivo perseguido hasta ahora por los colectivos feministas de Guinea Ecuatorial es despatriarcalizar la cultura de la opresión o de subordinación y desmintiendo los mitos y estereotipos creados para subyugar a la mujer. Despatriarcalizar la cultura implica inexorablemente desdibujar los espacios privado y público. En este sentido, hay que recordar que el espacio privado ha sido siempre el masculino, donde los hombres se reunían y forjaban la fraternidad en detrimento de la sororidad. El espacio privado solo era de los hombres porque allí se tomaban las decisiones importantes que afectarían a las mujeres y a los hombres. Cuando en 1979 las mujeres asaltan el abaa, espacio privado reservado únicamente para los hombres, comienza una nueva historia en las relaciones de género en Guinea Ecuatorial. Es a partir de esta fecha cuando realmente comienza surgir la conciencia feminista orientada a construir una sociedad distinta a la anterior.

Los diferentes períodos por los que ha trascurrido la lucha o resistencia contra el sistema patriarcal fang, nos hacen afirmar que ahora más que nunca se debe estabilizar los logros conseguidos para avanzar hacia otras metas donde la mujer deje de ser cosificada e infravalorada dentro de su cultura. En síntesis, los espacios privados y públicos están siendo desdibujados en la sociedad ecuatoguineana actual, pero queda mucho que hacer porque el sistema patriarcal todavía es robusto y se debe ir desmantelando para que no haya una regresión y que los varones se sientan con autoridad injustificada para imponer su voluntad a las mujeres. Si bien estamos ante una revolución feminista contra el sistema patriarcal fang, conviene que las mujeres sigan formándose más para luchar contra el patriarcado, exigiendo que sus derechos no sean socavados ni ultrajados.

\section{Bibliografía}

Alonso Pérez, Matilde y Elies Furió Blasco. (2007). El papel de la mujer en la sociedad española. Disponible en: https://hal.archives-ouvertes.fr/halshs-00133674 (Fecha de consulta: 15/02/21)

PÉrez ARMiÑo, Luis. (2018 ). "Y el sujeto se hizo verbo (aunque siempre fue objeto). La mujer fang en Guinea Ecuatorial y el impacto colonial». Anales del Museo Nacional de Antropología, XX. Madrid: Ministerio de Educación, Cultura y Deporte, 30-59.

Bituga-Nchama, Pedro Bayeme. (2020). La conflictividad de la ideología feminista en la cultura fang: una aproximación al estudio del patriarcado en Guinea Ecuatorial. Revista Cátedra, 3(1), 15-27.

Bituga-Nchama, Pedro Bayeme. (2020). Los estereotipos de género en la construcción de la mujer fang: Una educación patriarcal para la sumisión. Revista Cátedra,3(3), 143-160.

Bolekia BoleKÁ, Justo. (2003). Aproximación a la historia de Guinea Ecuatorial. Salamanca: Amarú. 
Bosch, Esperanza., \& Ferrer, Victoria. (2003). Fragilidad y debilidad como elementos fundamentales del estereotipo tradicional femenino. Feminismos, núm 2.

CAstells, Manuel. (1998). La era de la información. México: Siglo XXI.

Elósegui, María. (2011). Diez temas de género. Hombre y Mujeres ante los derechos productivos y reproductivos. Madrid: Ediciones Internacionales Universitarias.

Esono Mitogo, Pancracio. (1990). El hombre y la costumbre. Madrid: UNED.

IRrADIER, M. (1887). África. Viajes y trabajos de la Asosiación Euskera La Exploradora. Volumen II. Vitoria: La Exploradora.

MANuel, Castells. (2000). La era de la información. Volumen III: El poder de la identidad. México: Siglo XXI.

Mbana Nchama, J. (2016). Artículos escogidos: elementos socioculturales del pueblo fang. Madrid: APYCE S. L.

Mbana Nchama, Joaquín. (2011). Las imágenes públicas de la mujer fang en Guinea Ecuatorial. En Juan Ramón Aranzadi (coord.): II Jornadas de Antropología de Guinea Ecuatorial. Madrid. Universidad Nacional de Educación a Distancia, pp. 121-130

Nguema Bilogo, Longinos Eseng. (2012). La inculturación en el pueblo fang un paradigma de evangelización de África. Tesis de doctorado. Barcelona: Universidad de Barcelona.

Nsang Ovono, Carlota. (2018). Las formas del matrimonio bantú en Guinea Ecuatorial. Madrid: Dykinson, S.L.

Nvé Bengobesama, Constantino Ocháa. (1981). Tradiciones del pueblo fang. Madrid: RIALP, S.A.

Nzé Abuy, Rafael María. (1984). Nsoa o Dote Africana. Madrid: Instituto Politécnico Salesianos-Atocha.

Nze Aвuy, Rafael María. (1985). Familia y matrimonio fán. Madrid: Anzós, S. A.

Onofre de Alencar, Emanuela Cardoso. (2015). Mujeres y Estereotipos de género en la jurisprudencia de la Corte Interamericana de Derechos Humanos. Eunomía, Revista de Cultura en la Legalidad. $N^{\circ}$ 9, pp. 26-48.

TessmanN, Gunter. (2003). Los pamues (los fang). Alcalá de Henares: Ed. a cargo de José Manuel Pedrosa.

VAlcÁrcel, Amelia. (1991). Sexo y filosofía: sobre mujer y poder. Barcelona,: Anthropos.

VARELA, Nuria. (2005 ). Feminismo para principiantes. Barcelona: Ediciones B.

Recibido el 22 de mayo de 2020 Aceptado el 15 de febrero de 2021 BIBLID [1132-8231 (2021): 217-233] 